
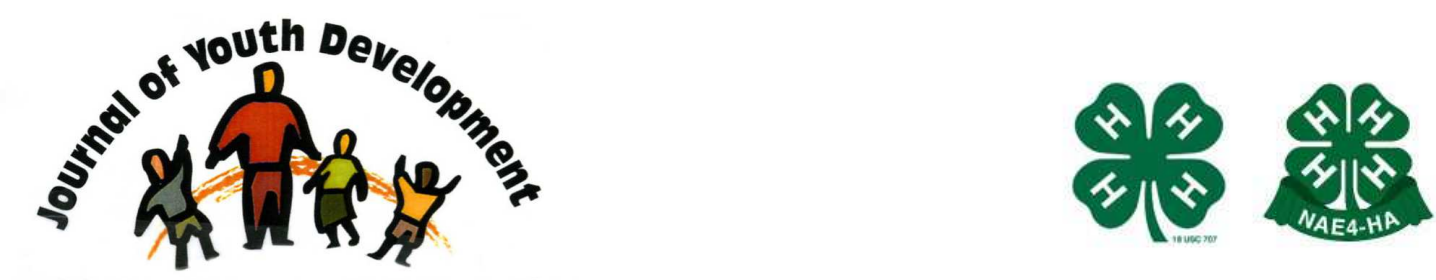

Bridging Research \& Practice

\title{
Computer Gaming and Student Achievement: Investigating Middle School Students' Behaviors
}

\author{
Vincent Ibanez \\ Texas A\&M University, Kingsville \\ Kingsville, TX \\ voibanez@ccisd.us \\ John R. Slate \\ Sam Houston State University \\ Huntsville, TX \\ profslate@netscape.net \\ Cheryl Kelsey \\ Texas A\&M University, Kingsville \\ kfclk00@tamuk.edu
}




\title{
JOURNAL OF YOUTH DEVELOPMENT \\ bridging research and practice

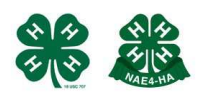

Volume 3, Number 3, Winter 2008

Article 080303RS002

\section{Computer Gaming and Student Achievement: Investigating Middle School Students' Behaviors}

\author{
Vincent Ibanez and Cheryl Kelsey \\ Texas A\&M University \\ John R. Slate \\ Sam Houston State University
}

\begin{abstract}
In spite of very little research on the subject, a growing concern exists among professionals that excessive time spent by students on computer gaming may have an undesirable effect in scholastic achievement. In this study, middle grade students selfreported their time spent on computer gaming for a one week time period. These self-reports were related with their GPAs at the end of the semester. Analysis of 114 students' GPAs in English, Math, and Science indicated the presence of a statistically significant difference in English GPAs between students in the High Computer Gaming group from students in the Moderate and Low Computer Gaming groups. No differences were yielded for Math or Science GPAs. Implications are discussed.
\end{abstract}

\section{Introduction}

Technology has become the newest tool in the education arsenal (Goss, 1996). Recently, researchers have shown that the average American classroom (K-12) has 4.0 students for every computer, with $98 \%$ of these classrooms having internet access (Information Please $\mathbb{}$ Database, 2007). American households have embraced technology as well. Computer use in private homes has increased steadily since their introduction in 1984 when merely $8.5 \%$ of households owned computers. By 2002, that number had increased to over $60 \%$ of households (Trumbull, 2005). Internet use has been embraced and has enhanced computer use by both schools and private homes (Newburger, 2001, p.4). Districts have renovated outdated classrooms and restructuring the curriculum to include technology at significant cost. 
The sudden influx of technology in the home and school has highlighted several areas of concern within the parenting and teaching community. Some researchers have focused on how technology can improve scholastics, how technology functions as a learning tool, and whether or not technology has any benefit at all within the teaching environment. Other areas of research have included how technology affects learning and how the brain develops under intensive multimedia sensory input. An area of particular concern to schools due to the immense popularity of specific entertainment technology is the extent to which computer gaming influences students' academic achievement.

Anderson and Dill (2000), in a study of video game playing and student academic achievement, reported the presence of a statistically significant negative relationship between the two variables. In contrast, Mitchell and Savill-Smith (2004) provided evidence that computer gaming can improve academic achievement. In addition, other researchers have demonstrated a positive relationship between computer gaming and attainment of fine motor skills, eye-hand coordination, visual attention, depth perception and computer competency (Reuters, 2007). Game sequences moving from a start to a finish require planning ahead and recognizing potential dilemmas along the path to completion. Circular games such as adventure games require multiple input sources, often from a variety of media. Cooperation with others to solve problems within the various environments requires ability to function within a society (Pillay, 2002).

Most students have been brought up spending substantially more than seven hours per week using the computer or another form of electronic media (Mitchell, \& Savill-Smith, 2004). Concerns are present when students spend excessive amounts of time in gaming technology. Negatives in gaming technology are both, physical and psychological. In video and computer games, players experience symptoms of stress including headaches, eyestrain, nausea, irritability, and exhaustion (Tazawa, Okada, Soukalo, \& Takada, 1997). Extensive playing, where the student spends hours at the monitor, produces evidence of sleep deprivation such as rings under the eyes and muscle fatigue in the neck or back (Tazawa, et al., 1997). Concerns have been expressed that electronic gaming affects the heart, causes carpal tunnel syndrome, and induces epileptic seizures. Excessive playing tends to aggravate these symptoms, where normal playing may be compared to light physical activity and have few negative effects (Emes, 1997).

Excessive gaming may also contribute to social isolation and other negative psychological effects (Roe, \& Muijs, 1998). Becoming proficient at a particular game artificially increases selfesteem causing the gamer to seek computer gaming interaction instead of human interaction. If a low feeling of self-esteem was already present, then the gaming success of the computer gamer generates a need to inflate their self-esteem through other addictive habits such as gambling. This process opens the door to depression and other psychological ills (Roe, \& Muijs, 1998).

As with all forms of entertainment, enough attraction may exist to the gaming media to cause a psychological dependency. On May 19, 2005, NBC News reported 13\% of adolescent gamers become addicted (Kem, 2005). The electronic gaming addict exhibits patterns of behavior which signal to teachers that a problem exists, generally a neglect of scholastic responsibilities and an obsession with computer games. 
Computer gaming provides middle school students with the opportunity to fantasize and explore different paths without ever leaving their bedrooms. Because they like to enjoy the moment, they often fail to think ahead (Jackson, \& Davis, 2000). Furthermore, computer gaming allows this age group to vicariously and safely experience the adventure and emotions inside them without the consequences of being seen as irresponsible.

\section{Purpose of Study}

The purpose of this study was to explore the relationship of computer gaming with the academic performance of middle school students. In particular, these researchers were interested in having students self-report time they spent using electronic media and then examining the extent to which these hours were related to student academic achievement in three core academic areas: English, Math, and Science.

\section{Research Questions}

1. What is the effect of computer gaming on sixth grade students' English Grade Point Averages?

2. What is the effect of computer gaming on sixth grade students' Math Grade Point Averages?

3. What is the effect of computer gaming on sixth grade students' Science Grade Point Averages?

\section{Methods and Procedures}

\section{Participants}

Out of a total pool of 181 sixth grade students enrolled in the Technology Applications class at a middle school in a Southwest state during the 2005-2006 school year, 114 students participated in this study. These students had consent forms returned with permission to participate and completed journals in which they logged their time playing games on electronic media. The school at which this study was conducted did not permit the collection of demographic data on these students. As such, no information is available regarding student gender or ethnicity.

\section{Procedures}

As part of this Technology Applications class, students were assigned the task of journaling and logging time for one week of technology use. In this journal, students were asked to record the times where they participated in any type of technological entertainment in television, radio, and electronic games (including computers, television console games, and handheld gaming devices). Within the journal was a section specifically designated for computer gaming which was the section of the journal that was used for this study. Grades for the core subject areas and final grade point averages were obtained at the end of the spring semester.

\section{Results}

Descriptive statistics were calculated for students' GPAs in English, Math, Science, and then overall, as well as for the hours students reported they spent that week in computer gaming activities. Students' GPAs across the three areas were very consistent. Computer gaming varied from a low of 0 hours to a maximum reported 80 hours. Table 1 depicts these values. 
Table 1

Descriptive Statistics for Subject Areas and Hours of Game Playing ( $\mathrm{N}=114)$

\begin{tabular}{|l|c|c|}
\hline Area & M (0 to 100) & SD \\
\hline English GPA & 83.07 & 7.73 \\
\hline Math GPA & 83.34 & 8.93 \\
\hline Science & 83.66 & 6.51 \\
\hline Average & 83.36 & 6.80 \\
\hline Hours of Computer Gaming & 27.93 & 23.69 \\
\hline
\end{tabular}

Following a frequency table of hours students spent computer gaming, three groups were created: a Low Computer Gaming group which was comprised of 34 students whose computer gaming hours ranged from 0 to 10 hours that week; a Moderate Computer Gaming group which was comprised of 35 students whose computer gaming hours ranged from 11 to 29 hours that week; and, finally a High Computer Gaming group, comprised of 45 students whose computer gaming hours ranged from 30 to 80 hours that week. Descriptive statistics were then calculated for their GPAs by group membership. For this study, students' GPAs were defined by their percentage success out of $100 \%$ that was possible for each course. That is, an average GPA of $80 \%$ in English meant that $80 \%$ of $100 \%$ points were received. Table 2 depicts these values.

Table 2

Descriptive Statistics for Subject Areas by Group Membership

\begin{tabular}{|l|c|c|c|}
\hline Area & Low & Moderate & High \\
\hline English GPA & $85.29(6.81)$ & $83.86(7.48)$ & $80.78(8.11)$ \\
\hline Math GPA & $84.47(9.13)$ & $84.23(7.85)$ & $81.80(9.52)$ \\
\hline Science & $83.85(6.83)$ & $84.31(6.62)$ & $83.00(6.27)$ \\
\hline Average GPA & $84.54(6.81)$ & $84.13(6.36)$ & $81.86(6.99)$ \\
\hline
\end{tabular}

To address whether these three groups of students differed in their GPAs, univariate analyses of variance (ANOVA) procedures were calculated. An ANOVA, used to ascertain the extent to which a statistically significant difference was present among the three groups of computer gaming in their English GPAs, yielded a statistically significant finding, $F(2,111)=3.738$, $p=.027, d=.25$. Scheffe post hocs revealed that students in the High computer gaming group had statistically lower English GPAs than did students in either the Moderate or the Low computer gaming groups, about 4.5 points lower. The effect size for this finding was moderate (Cohen, 1988). 
A similar analysis, an ANOVA, was conducted to determine the extent to which a statistically significant difference was present among the three groups of computer gaming in their Math GPAs. This analysis did not yield a statistically significant finding, $F(2,111)=1.117, p=.331$. Students in the High computer gaming group had lower Math GPAs, albeit not statistically significantly lower, than did students in either the Moderate or the Low computer gaming groups, about 3 points lower. A similar analysis in which Science GPAs were investigated also failed to yield statistical significance, $F(2,111)=0.418, p=.659$. Science GPAs did not differ across the three groups of students.

\section{Discussion}

These authors investigated the extent to which computer gaming was related with students' GPAs in English, Math, and Science. Though not related with Math and Science GPAs, results were statistically significant with students' English GPAs. Students in the High Computer Gaming group performed statistically lower, about 4.5 points lower, in English than students in either the Moderate or the Low Computer Gaming groups. Thus, this study provides some evidence of a connection between time spent on technology usage and student academic achievement.

As such, these findings support the findings of Anderson and Dill (2000) of a negative relationship between hours spent gaming and student academic achievement, at least in the area of English. Though tentative in nature, researchers are recommended to investigate this issue using more rigorous methods. Gathering data on hours spent computer gaming throughout the semester might provide more in-depth information than was obtained in this one week of self-reported computer gaming hours. In addition, more information should be acquired concerning the types of computer gaming activities in which students are involved. To what extent could some computer gaming activities be considered educational in nature, versus entertainment, versus socializing? Until further research studies are conducted, readers are urged to view these findings as tenuous and only suggestive of a possible linkage between hours spent on computer gaming and student academic achievement.

The evidence of a connection between time spent on technology usage and student achievement among middle school student merits further research. Adolescents are at unique developmental stage and should be exposed to the widest range of intellectual, social, and physical experiences (Jackson, \& Davis, 2000). Computer gaming may decrease the opportunities for exploring and developing not only cognitive ability but also physical, social, and emotional skills.

\section{References}

Anderson, C.A., \& Dill, K. (2000, April). Video games and aggressive thoughts, feelings, and behavior in the laboratory and in life. Journal of Personality and Social Psychology, 78(4), 772790.

Cohen, J. (1988). Statistical power analysis for the behavioral sciences (2nd ed.). Hillsdale, NJ: Lawrence Erlbaum. 
Emes, C.E. (1997). Is Mr Pac Man eating our children? A review of effect of video games on children. Retrieved June 24, 2008 from: http://ww1.cpa-apc.org:8080/publications/archives/PDF/1997/May/EMES.pdf

Goss, M.A. (1996, Spring 1996). Releasing the isolated warrior. Retrieved March 3, 2006, from: http://www.newhorizons.org/strategies/technology/goss.htm

Information Please $\Re$ Database. (2007, March 6). Retrieved March 6, 2007, from: http://www.infoplease.com/askeds/computers-public-schools.html

Jackson, A., \& Davis, G. (2000). Turning Points 2000. New York: Teachers College Press.

Kem, L. (2005). Gamer addiction: A threat to student success! What advisors need to know. Retrieved November 20, 2005, from:

http://www.nacada.ksu.edu/Clearinghouse/AdvisingIssues/Gamer-Addiction.htm

Mitchell, A., \& Savill-Smith, C. (2004). The use of computer and video games for learning. Retrieved November 8, 2005, from: http://www.Isda.org.uk/files/PDF/1529.pdf

Newburger, E.C. (2001, September). Home computers and internet use in the United States:August 2000. Retrieved December 25, 2006, from: http://www.census.gov/prod/2001pubs/p23-207.pdf

Pillay, H. (2002). An investigation of cognitive processes engaged in by recreational computer game players: implications for skills of the future. Journal of Research on Technology in Education, 34(3), 336-350.

Reuters. (2007, February 20). Action video tames sharpen vision 20 percent. Retrieved Feb 24, 2007, from: http://www.sciencedaily.com/releases/2007/02/070206100601.htm

Roe, K., \& Muijs, D. (1998). Children and computer games: A profile of the heavy user. European Journal of Communication, 13(2), 181-200.

Tazawa, Y., Okada, K., Soukalo, A., \& Takada, G. (1997). Excessive playing of home computer games by children presenting unexplained symptoms. The Journal of Pediatrics, 13066), 10101011.

Trumbull, M. (2005). Poverty now comes with a color tv. Retrieved January 1, 2007, from: http://articles.moneycentral.msn.com/Investing/Extra/PovertyNowComesWithAColorTV.aspx

(C) Copyright of Journal of Youth Development Bridging Research and Practice. Content may not be copied or emailed to multiple sites or posted to a listserv without copyright holder's express written permission. Contact Editor at: patricia.dawson@oregonstate.edu for details. However, users may print, download or email articles for individual use.

ISSN 2325-4009 (Print); ISSN 2325-4017 (Online) 